\title{
Correlation between Serum Level of Matrix Metalloproteinase-2 with Left Ventricular End-diastolic Volume in Children with Heart Failure
}

Bagus Ngurah Mahakrishna*, Eka Gunawijaya, I Wayan Dharma Artana, Ni Putu Veny Kartika Yantie, Made Kardana, I Putu Gede Karyana, Gusti Ayu Putu Nilawati

Department of Child Health, Medical School, Universitas Udayana, Sanglah Hospital, Denpasar, Bali, Indonesia

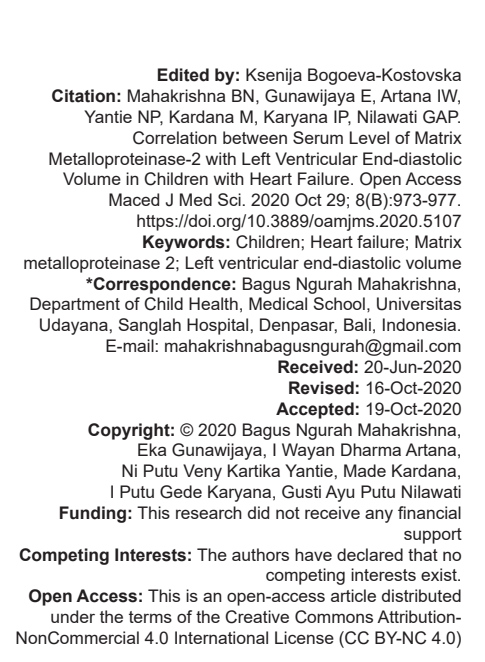

\begin{abstract}
BACKGROUND: Left ventricular end-diastolic volume (LVEDV) on echocardiography is one of the tests performed on heart failure. This refers to the volume of the left ventricle at the end of the diastolic phase, which would be increased when there is a disturbance in preload, afterload, and contractility factors. Matrix metalloproteinase-2 (MMP2) is a marker of congestive heart failure that can be examined through laboratory examinations.

AIM: The objective of the study was to provide evidence of the association between MMP and inflammatory process as well as its correlation with LVEDV in children with heart failure.

METHODS: This was a cross-sectional study conducted on children aged 3 months-12 years old with heart failure, who visited Sanglah Hospital, Denpasar, Indonesia from May 2017 to March 2018. Echocardiographic examination (LVEDV) and blood samples were taken to measure the serum level of MMP2 on day 1 after the subjects were diagnosed with heart failure.

RESULTS: A total of 32 subjects with heart failure were analyzed in this study. Acyanotic congenital heart defect (CHD) was the most common cause of heart failure, as observed in 23 subjects $(71.9 \%)$. Characteristics data revealed that 24 subjects $(75 \%)$ were underweight, $23(71.9 \%)$ had cardiomegaly, and $22(68.8 \%)$ had mild heart failure. Data analysis showed a moderate positive correlation between MMP2 levels with LVEDV after controlling for the influence of age $(p=0.02 ; r=0.425)$

CONCLUSION: There was a moderate positive correlation between MMP2 level and LVEDV after controlling for the age factor.
\end{abstract}

\section{Introduction}

Heart failure is a public health problem that causes high morbidity and mortality in the world [1]. The incidence of heart failure due to cardiac structural abnormalities such as congenital heart disease is around 1-2 in 1000 live births, with the highest incidence occurring in the $1^{\text {st }}$ year of life [2], [3], [4].

The diagnosis of heart failure in children is based on Ross criteria. These criteria have been modified to provide a general assessment in the severity of heart failure in children [3], [4], [5].

Left ventricular end-diastolic volume (LVEDV) on echocardiography is one of the tests performed on heart failure. This is the volume of the left ventricle at the end of the diastolic phase, which would be increased when there is a disturbance in the preload, afterload, and contractility factors. Laboratory tests for markers of heart failure are needed to support the diagnosis, including matrix metalloproteinase (MMP). The MMPs are a large family of $\mathrm{Zn}^{2+}$ enzymes responsible for tissue remodeling, vascular remodeling, and degradation of the extracellular matrix in various diseases [6].

Matrix metalloproteinase that is typically increased in patients with heart failure is MMP2. An increase in MMP2 above themean serum level is associated with significantly high mortality and poor prognosis in patients with heart failure [7].

In patients with heart failure, the serum level of MMP2 was typically above the normal range in the decompensated state and is rapidly decreased throughout the process of compensation. The production of MMP is affected by several mechanisms, including changes in hemodynamic, neurohormonal, and inflammatory factors. Neurohormonal factors such as catecholamines and angiotensin II were increased in heart failure. Elevated plasma norepinephrine level activates the renin-angiotensin in the myocardium, and angiotensin II increases the level of MMP in heart failure [7]. The renin-angiotensin system increases the plasma level of angiotensin II. These hormonal changes will increase preload and afterload in the heart and play a role in cardiac remodeling which is considered to be the underlying cause of heart failure [8]. 
The association between oxidative stress and MMP also influences the mechanism of heart failure. Reactive oxygen species (ROS) activates pro-MMP and contributes to the activation of regulatory factors such as nuclear factor $\kappa \mathrm{B}(\mathrm{NF}-\kappa \mathrm{B})$ and activator protein-1 (AP-1). Mediators such as angiotensin II and endothelin I directly or indirectly affect the myocardium, which leads to heart failure [9].

MMP2 levels have increased significantly in patients with heart failure compared to normal adults [10]. The aim of this study is to prove that MMP2 level is increased in children with heart failure.

\section{Methods}

This was an observational study with a crosssectional design to determine the correlation between serum level of MMP2 with left ventricular end-diastolic volume in children with heart failure.

This study was conducted from May 2017 to March 2018 in the Pediatric Ward of Sanglah Hospital, Denpasar, Indonesia. Examination of serum MMP2 level was performed at Prodia Denpasar Laboratory.

\section{Eligibility criteria}

The subjects in this study were children aged 3 months-12 years with heart failure, who fulfilled the inclusion and exclusion criteria. Inclusion criteria include children with heart failure due to acyanotic heart disease aged 3 months-12 years. Exclusion criteria include patients with comorbidities such as sepsis, renal failure, diabetic ketoacidosis, and cancer.

\section{Procedure}

Sampling was conducted through consecutive random sampling until the number of samples was reached.

Subjects with heart failure, who fulfilled the eligibility criteria were given complete information regarding this study and were asked for their willingness to participate in the study and signed the informed consent after receiving and understanding the information provided. Echocardiographic examination (LVEDV) was performed by 1 pediatric cardiology consultant, and blood samples were taken to measure the serum level of MMP 2. The measurement serum level of MMP2 using the Quantikine Immunoassay method. Laboratory measurements were conducted by
Prodia laboratory staff on day I after the subjects were diagnosed with heart failure.

Heart failure was diagnosed based on the Ross criteria, and diagnoses were made by a pediatric cardiology consultant at Sanglah General Hospital, Denpasar, Indonesia. Based on the Ross score, we divided into four groups: Those with scores of 0-2 were without heart failure, those with scores of 3-6 were diagnosed as mild heart failure, those with scores of 7-9 were diagnosed as moderate heart failure, and those with scores of 10-12 were diagnosed with severe heart failure [5].

MMP2 is an endopeptidase family that was typically increased in heart failure. The level of MMP2 in the serum was examined using the Quantikine Immunoassay method, with a standard range of 0.5-32 ng/ml. A serum MMP level of $>32 \mathrm{ng} / \mathrm{ml}$ was considered increased. LVEDV is the volume of the left ventricle at the end of the diastolic phase, as measured through echocardiography performed by a pediatric cardiology consultant, using a modified Simpson technique. Results were expressed in $\mathrm{ml} / \mathrm{m}^{2}$.

\section{Statistics}

Data were analyzed using a statistical program: The normality of the study was tested using the ShapiroWilk test. Descriptive analysis was performed on the characteristics of the subjects. Correlation analysis was conducted for data with normal distribution using the Spearman correlation test, with a $p<0.05$ considered statistically significant.

\section{Ethical aspect}

This study was approved by the ethical committee of Sanglah Hospital, with protocol number 1027/UN.14.2/KEP/2017.

\section{Results}

This study was conducted from May 2017 to March 2018 in the Pediatric Ward at Sanglah Hospital, Denpasar, Indonesia. During the study period, there were 32 children with heart failure who fulfilled the inclusion criteria.

Characteristics of subjects are shown in Table 1, including gender, age, type of heart disease, nutritional status, cardiomegaly, and heart failure score. The most common cause of heart failure in the study was acyanotic heart disease, which was observed in 23 subjects $(71.9 \%)$. 
Table 1: Characteristics of subjects

\begin{tabular}{ll}
\hline Characteristics & $\mathrm{n}=32$ \\
\hline Gender, $\mathrm{n}(\%)$ & $12(37.5)$ \\
Male & $20(62.5)$ \\
Female & \\
Age (years), median & $13(40.7)$ \\
$\quad$ < years & $5(15.6)$ \\
$1-5$ years & $14(43.7)$ \\
$>5$ years & \\
Heart disease, $\mathrm{n}(\%)$ & $24(75)$ \\
Acyanotic CHD & $13(40.6)$ \\
VSD & $10(31.3)$ \\
PDA & $1(3.1)$ \\
ASD & $1(3.1)$ \\
Cardiomyopathy & $1(3.1)$ \\
Dilated & $7(21.9)$ \\
Acquired heart disease (RHD) & \\
Nutritional status, $\mathrm{n}(\%)$ & $7(21.9)$ \\
Well-nourished & $24(75.0)$ \\
Underweight & $1(3.1)$ \\
Severe malnutrition & \\
Cardiomegaly, $\mathrm{n}(\%)$ & $23(71.9)$ \\
Yes & $9(28.1)$ \\
No & \\
Ross criteria, $\mathrm{n}(\%)$ & $22(68.8)$ \\
Mild & $9(28.1)$ \\
Moderate & $1(3.1)$ \\
Severe &
\end{tabular}

\section{Characteristics of heart failure score}

The most common physical examination finding in heart failure as measured using Ross criteria was tachypnea (22 subjects). Heart failure characteristics based on Ross criteria are presented in Table 2.

Table 2: Characteristics of heart failure

\begin{tabular}{ll}
\hline Characteristics & $\mathrm{n}=32$ \\
\hline Diaphoresis, $\mathrm{n}(\%)$ & $19(59.4)$ \\
Head only, at exertion & $12(37.5)$ \\
Head and body at exertion & $1(3.1)$ \\
Head and body at rest & $10(31.3)$ \\
Tachypnea, $\mathrm{n}(\%)$ & $18(56.3)$ \\
$\quad$ Rare & $4(12.5)$ \\
$\quad$ Several times & \\
Frequent & $1(3.1)$ \\
Breathing, $\mathrm{n}(\%)$ & $30(93.8)$ \\
$\quad$ Normal & $1(3.1)$ \\
Retractions & $0(0)$ \\
Dyspnea & $22(68.8)$ \\
Respiratory rate, $\mathrm{n}(\%)$ & $10(31.3)$ \\
$\quad$ Normal & \\
Fast & $2(6.3)$ \\
Very fast & $21(65.6)$ \\
Heart rate, $\mathrm{n}(\%)$ & $9(28.1)$ \\
$\quad$ Normal & \\
Fast & $17(53.1)$ \\
Very fast & $11(34.4)$ \\
Hepatomegaly, $\mathrm{n}(\%)$ & $4(12.5)$ \\
\hline <2 cm & \\
$2-3 \mathrm{~cm}$ &
\end{tabular}

\section{Correlation between serum MMP2 level}

\section{and LVEDV}

Table 3 showed the normality test of MMP2 level and LVEDV preceding the correlation analysis. The distribution of LVEDV data, as shown in the table, was non-normally distributed with a $p=0.003$. Median LVEDV was 60.1 with IQR of 60.6. Data distribution for

Table 3: Normality test of LVEDV and serum MMP2 level

\begin{tabular}{lll}
\hline Variable & Mean (SD) & $\mathrm{p}$ \\
\hline LVEDV $(\mathrm{ml})$ & $68.98 \pm 45.27$ & 0.003 \\
Serum level of MMP 2 $(\mathrm{ng} / \mathrm{dl})$ & $324 \pm 103.1$ & 0.296 \\
\hline
\end{tabular}

serum level of MMP 2 was normal with a mean of 324 , and $a p=0.296$.

Spearman correlation test was used due to the fact that not all of the data were normally distributed. Data analysis revealed there was no correlation between serum level of MMP2 and LVEDV in children with heart failure, with a $p=0.873$. An analysis was performed to determine whether age affected LVEDV; thus, a partial correlation analysis was performed. The analysis revealed a correlation between serum level of MMP2 with LVEDV after controlling for the influence of age, with a $p=0.02$. The result of this analysis is shown in Table 4.

Table 4: Partial correlation between MMP2 and LVEDV before and after controlling for age factor

\begin{tabular}{llll}
\hline Variable & Adjustment & LVEDV & \\
\cline { 3 - 4 } & & $\mathrm{r}$ coefficient & p value \\
\hline MMP2 & Non-adjusted & -0.029 & 0.873 \\
MMP2 & Age-adjusted & 0.406 & 0.02 \\
\hline
\end{tabular}

Figure 1 presented a scatter plot diagram of the partial correlation analysis, which showed a moderate correlation between serum level of MMP2 and LVEDV after controlling for age with an $r$ value $=0.425$. The analysis revealed a significant correlation between serum level of MMP2 and LVEDV in subjects aged 2 years and above.

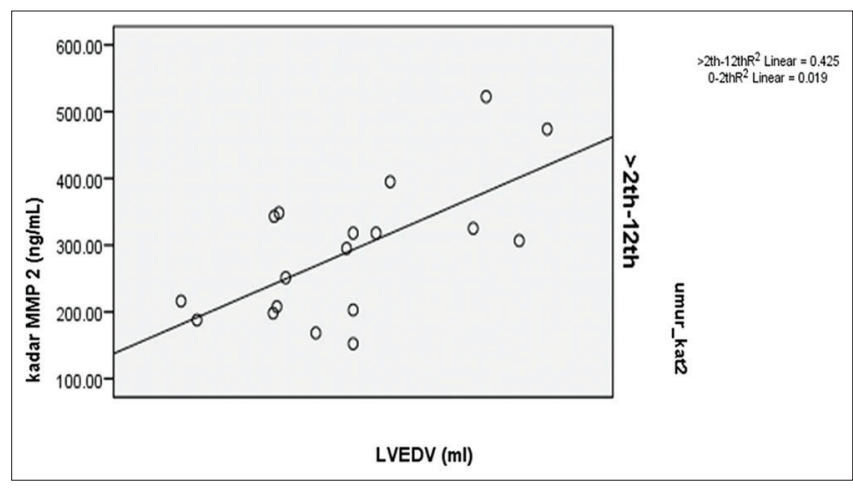

Figure 1: Scatter plot diagram of a partial correlation between MMP2 and LVEDV in children $>2$ years old

\section{Discussion}

A total of 32 subjects participated in this study. Most of the subjects were female (20 subjects), and a majority of the subjects belong to the $>5$ years age group. Sani et al. found that rheumatic heart disease was the most common heart disease in children $>5$ years of age $(42.7 \%)$ [11]. In this study, we found that the most prevalent heart disease was congenital heart disease, which made up for $75 \%$ of all cases.

The most common cause of heart failure in children was congenital heart disease (CHD). Ventricular septal defect is the most common CHD observed in 
children. In this study, we found that the most common cause of heart failure was VSD. Similarly, Abdulkadir et al. also found that the most prevalent CHD in children was VSD (40.6\%) [12].

Malnutrition is a very common problem in children with CHD [13]. High basal metabolic rate and inadequate nutrient intake are the main causes of malnutrition in children with CHD [14]. In this study, we found that most subjects (24 subjects, $75 \%$ ) were underweight. Similarly, Isezuo et al. found that $72.9 \%$ of children with CHD were underweight [15].

Diagnoses of heart failure were made using modified Ross Criteria. In this study, we found that most subjects had mild heart failure (22 subjects, 68.8\%). Based on characteristics data, the most common symptoms were retraction $(93.8 \%)$, rapid respiratory rate $(68.8 \%)$, tachycardia $(65.6 \%)$, diaphoresis in the head during activities (59.4\%), tachypnea (56.3\%), and hepatomegaly of $<2 \mathrm{~cm}(53.1 \%)$.

Left ventricular end-diastolic volume (LVEDV) is the volume of the left ventricle at the end of the diastolic phase, which would be increased when there is a disturbance in preload, afterload, and contractility factors. Increased LVEDV results in increased heart load, causing the body to perform a compensation mechanism. When the heart compensation mechanism failed, a decompensation mechanism occurs which results in ROS activation, which then activates MMP production. The production of MMP is affected by neurohormonal factors, such as catecholamines and angiotensin II, which were typically increased in heart failure. Elevated plasma norepinephrine level activates the renin-angiotensin in the myocardium, and angiotensin II increases the level of MMP in heart failure [7]. The renin-angiotensin system increases the plasma level of angiotensin II. These hormonal changes will increase preload and afterload in the heart and play a role in cardiac remodeling which is considered to be the underlying cause of heart failure [8].

The current study on the correlation between MMP2 and LVEDV in children with heart failure is the first conducted in children. A study by Cheng et al. in pediatric population showed a significant increase in serum level of MMP2 in CHD children with VSD compared to the control group, with a $p<0.01$ [16]. Another study by Kinc et al. on pediatric population with $\mathrm{CHD}$ showed that there was no significant increase in serum level of MMP in the cyanotic CHD group compared to the control group [17]. A study by Yamazaki et al. in adult population showed that the serum level of MMP2 was significantly higher in patients with severe heart failure than in patients with mild heart failure, with a $p<0.01$ [18]. Another study by Shirakabe et al. in the adult population with acquired heart disease showed that serum level of MMP2 was significantly higher in patients with heart failure on the $1^{\text {st }}$ day. Serum level of MMP2 was significantly decreased on the third day compared to the $1^{\text {st }}$ day with a $p<0.001$ [7]. In this study, we found that there was no correlation between serum level of MMP2 and LVEDV in children with heart failure ( $p=0.873$ ). This finding may be due to some of the samples for MMP2 level examination was taken after the $1^{\text {st }}$ day of the decompensation phase of heart failure. Serum level of MMP2 was found to be increased in the decompensation phase of heart failure [7].

\section{Correlation between serum level of MMP2 and LVEDV in children with heart failure after controlling for age}

Matrix metalloproteinase is associated with diastolic dysfunction and heart failure [19]. Diastolic function is an important component of the left ventricular function that can cause symptoms of heart failure [20]. The mechanism underlying heart failure includes impaired cardiac contractility, which results in lowerthan-normal cardiac output [21]. The decreased cardiac output is due to decreased contractility, increased afterload, or increased preload, resulting in decreased ejection fraction and increased LVEDV. Age is one of the factors that affect LVEDV. This is due to the fact that with increasing age, structural, and functional changes in the heart also increases. Functional changes and compensation mechanisms that occur with increasing age include changes in heart rate, cardiac systolic function, cardiac diastolic function, and contractility. Normal diastolic filling can be divided into two phases, namely the passive (represented by the "E wave" on echocardiographic study of transmitral flow) and active (represented by an A wave and produced by atrial contraction) phases. Diastolic filling phase becomes slower with age, resulting in a difference in the proportion of diastolic filling in the passive phase. As the bulk of ventricular filling shifts to later in diastole and there is significant atrial enlargement with aging, the atrium contributes a greater portion of the total LVEDV [22].

In this study, we found that the younger the age of the child, the lower the value of LVEDV. A study by Cain et al. showed an increase in LVEDV in adolescence, and there were no significant differences between the sexes with a $p=0.65$ [23]. In this study, we found a correlation between serum level of MMP2 with LVEDV after controlling for age with a $p=0.02$. We also obtained significant results in subjects over 2 years of age. The scatter plot graph (Figure 1) showed a moderate correlation between serum level of MMP2 and LVEDV after controlling for age factor with an $r$ of 0.425.

\section{Conclusion}

This study showed a moderate positive correlation between MMP2 levels with LVEDV after controlling the influence of age. 


\section{Acknowledgment}

The authors would like to thank Sanglah General Hospital Denpasar Bali, Indonesia and the parents of patients who have been willing to participate in this study.

\section{References}

1. Mueller GC, Schlueter EL, Arndt F, Khatami JW, Mir TS. Prevalence of anemia in children with congestive heart failure due to dilated cardiomyopathy. Int J Pediatr. 2012;2012:452909. https://doi.org/10.1155/2012/452909

PMid:23213342

2. Beggs S, Thompson A, Nash R, Tompson A, Peterson G. Cardiac Failure in Children. $17^{\text {th }}$ Expert Committee on the Selection and Use of Essential Medicines. Geneva: World Health Organization; 2009. p.1-31.

3. Hsu DT, Pearson GD. Heart failure in children: Part I: History, etiology, and pathophysiology. Circ Heart Fail. 2009;2:63-70. https://doi.org/10.1161/circheartfailure.108.820217 PMid:19808316

4. Frobel AK, Hulpke WM, Schmidt KG, Laer S. Beta blockers for congestive heart failure in children. Cochrane Database Syst Rev. 2009;1:CD007037. https://doi.org/10.1002/14651858. cd007037.pub2

PMid:19160314

5. Ross RD. The ross classification for heart failure in children after 25 years: A review and an age stratified revision. Pediatr Cardiol. 2012;33(8):1295-300. https://doi.org/10.1007/ s00246-012-0306-8

PMid:22476605

6. Verma RP, Hansch C. Matrix metalloproteinases (MMPs): Chemical-biological functions and (Q)SARs. Bioorg Med Chem. 2007;15(6):2223-68. https://doi.org/10.1016/j.bmc.2007.01.011 PMid: 17275314

7. Shirakabe A, Asai K, Hata N, Yokoyama S, Shinada T, Kobayashi $\mathrm{N}$, et al. Clinical significance of matrix metalloproteinase (MMP)-2 in patients with acute heart failure. Int Heart J. 2010;51(6):404-10. https://doi.org/10.1536/ ihj.51.404

PMid:21173516

8. Muller AL, Dhalla AS. Role of various proteases in cardiac remodeling and progression of heart failure. Heart Fail Rev. 2012;17(3):395-409. https://doi.org/10.1007/ s10741-011-9269-8 PMid:21739365

9. Tousoulis D, Kampoli AM, Papageorgiou N, Antoniades C, Siasos G, Latsios G, et al. Matrix metalloproteinases in heart failure. Curr Top Med Chem. 2012;12(10):1181-91. https://doi. org/10.2174/1568026611208011181 PMid:22519448

10. Banfi C, Cavalca V, Veglia F, Brioschi M, Barcella S, Mussoni L, et al. Neurohormonal activation is associated with increased levels of plasma matrix metalloproteinase 2 in human heart failure. Eur Heart J. 2005;26(5):481-8. https://doi.org/10.1093/ eurhearti/ehi073

PMid:15618033

11. Sani UM, Ahmed H, Jiya NM. Pattern of acquired heart diseases among children seen in Sokoto, North-Western Nigeria. Niger J Clin Pract. 2015;18(6):718-25. https://doi. org/10.4103/1119-3077.163284

PMid:26289507

12. Abdulkadir M, Abdulkadir Z. A systematic review of trends and patterns of congenital heart disease in children in Nigeria from 1964-2015. Afr Health Sci. 2016;16(2):367-77. https://doi. org/10.4314/ahs.v16i2.5

PMid:27605952

13. Hassan BA, Albanna EA, Morsy SM, Siam AG, Shafie MM, Elsaadany HF, et al. Nutritional status in children with un-operated congenital heart disease: An Egyptian center experience. Front Pediatr. 2015;3:53. https://doi.org/10.3389/ fped.2015.00053

PMid:26125014

14. Ratanachu S, Pongdara A. Nutritional status of pediatric patients with congenital heart disease: Pre and post cardiac surgery. J Med Assoc Thai. 2011;94(3):S133-7.

PMid:22043766

15. Isezuo KO, Waziri UM, Sani UM, Garba BI, Ahmad MM, Adamu A, et al. Nutritional status of children with congenital heart diseases at a university teaching hospital, North-Western Nigeria. Int J Trop Dis Health. 2017;25(4):1-8. https://doi. org/10.9734/ijtdh/2017/35964

16. Cheng KS, Liao YC, Chen MY, Kuan TC, Hong YH, Ko L. Circulating matrix metalloproteinase 2 and 9 enzyme activities in the children with ventricular septal defect. Int J Biol Sci. 2013;9(6):557-63. https://doi.org/10.7150/ijbs.6398

PMid:23847438

17. Kihc Z, Ucar B, Ozdemir G, Colak O, Bal C, Ertugrul T. Circulating matrix metalloproteinase and tissue inhibitors of metalloproteinases levels in pediatric patients with congenital heart disease: Relationship to cardiac functions. Anatol J Cardiol. 2014;14(6):531-41. https://doi.org/10.5152/akd.2014.4950 PMid:25233500

18. Yamazaki T, Lee JD, Shimizu H, Uzui H, Ueda T. Circulating matrix metalloproteinase 2 is elevated in patients with congestive heart failure. Eur J Heart Fail. 2004;6:41-5. https:// doi.org/10.1016/j.ejheart.2003.05.002

PMid: 15012917

19. Baggen VJ, Eindhoven JA, Bosch AE, Witsenburg $M$, Cuypers JA, Langstraat JS, et al. Matrix metalloproteinase as candidate biomarkers in adults with congenital heart disease. Biomarkers. 2016;21(5):466-73. https://doi.org/10.3109/13547 50x.2016.1153722

PMid:26983903

20. Panesar DK, Burch M. Assessment of diastolic function in congenital heart disease. Front Cardiovasc Med. 2017;4:5. https://doi.org/10.3389/fcvm.2017.00005

PMid:28261582

21. Figueroa MS, Peters JI. Congestive heart failure: Diagnosis, pathophysiology, therapy, and implications for respiratory care. Respir Care. 2006;51(4):403-12.

PMid:16563194

22. Strait JB, Lakatta EG. Aging-associated cardiovascular changes and their relationship to heart failure. Heart Fail Clin. 2012;8(1):143-64. https://doi.org/10.1016/j.hfc.2011.08.011 PMid:22108734

23. Cain PA, Ahl R, Hedstrom E, Ugander M, Johnsson AA, Friberg $P$, et al. Age and gender specific normal values of left ventricular mass, volume and function for gradient echo magnetic resonance imaging: A cross sectional study. BMC Med Imaging. 2009;9:2. https://doi.org/10.1186/1471-2342-9-2

PMid:19159437 